\title{
EXPERIMENTAL CANDIDOSIS: PAW OEDEMA IN THE ANALYSIS OF A LOCAL INFECTION
}

\author{
T. E. Miller and GlenNe Findon
}

\author{
Department of Medicine, Auckland Hospital, Park Road, Auckland, New Zealand
}

\begin{abstract}
Summary. Existing models of Candida albicans infection are semiquantitative and do not allow continuous observations to be made on individual animals. We have used the inflammatory response in the footpad as an indirect measure of the number of yeast cells in a localised lesion. C. albicans infection of the footpad has been used in series of experiments in which changes in yeast-cell numbers in the local lesion have been compared with the degree of footpad oedema. Studies in animals treated with cyclophosphamide or amphotericin have confirmed that paw oedema parallels yeast-cell numbers in the local lesion. This quantitative approach will be helpful in the study of localised infection with $C$. albicans and other fungi and in the evaluation of antifungal agents.
\end{abstract}

\section{INTRODUCTION}

Recent investigations into the effect of uraemia on host resistance to Candida albicans required a model of a localised infection that allowed continuous observations to be made on individual animals. Several models were considered (Pearsall and Lagunoff, 1974; Ray and Wuepper, 1976; Sohnle et al., 1976; Giger et al., 1978; Poor and Cutler, 1981) but proved unsuitable because they were either non-quantitative, did not permit multiple observations or were ethically unacceptable.

Previous experience with the carrageenin-induced oedema model (Winter et al., 1962) in the assessment of anti-inflammatory drugs suggested that the inflammatory response to infection in the rodent footpad could be related to the number of colony-forming units (cfu) of $C$. albicans. We have measured footpad oedema, following a local challenge, as a convenient, accurate and simple measure of the number of yeast cells in the lesion.

\section{MATERIALS AND METHODS}

Animals. Male and female rats from an inbred strain of Dark Agouti rats, which weighed 200-250 g, were used in these experiments.

Yeast strain. A culture of $C$. albicans from a clinical specimen was obtained from Auckland Hospital. Cultures were maintained in Sabouraud dextrose broth at $-20^{\circ} \mathrm{C}$ and subcultured monthly on to Sabouraud dextrose agar for storage at $4^{\circ} \mathrm{C}$. The cultures used for the experiments were grown overnight in nutrient broth at $37^{\circ} \mathrm{C}$ and washed three times in sterile normal saline. Cell concentration was adjusted after counting yeast cells with an improved Neubauer counting 
chamber. The number of viable organisms was confirmed by colony counts in serial ten-fold dilutions in pour-plates of Sabouraud's dextrose agar.

Induction of infection. Yeast cells were suspended in $20 \mu \mathrm{l}$ of sterile normal saline and injected intradermally into the plantar tissue of the hind foot of lightly anaesthetised rats by a 26-gauge needle and a $0 \cdot 1 \mathrm{ml}$ Hamilton syringe. Great care was taken not to administer the organisms subcutaneously (Gray and Jennings, 1955). Injections were made into the footpads of both hind feet in all rats.

Measurement of footpad oedema. Footpad thickness was measured centrally between the dorsal and plantar surfaces by a dial micrometer (model 7309, range 0.01-9.00 $\mathrm{mm} \pm 0.01 \mathrm{~mm}$, Mitutoyo Mfg. Co. Ltd, Tokyo, Japan) which was modified to avoid pressure on the swollen tissue by reducing the spring tension. Before injecting the yeast suspensions, a base-line thickness for each footpad was measured. After injection, the footpads were measured daily and the increase in thickness expressed as a percentage of the baseline value. To establish the error of the procedure, the footpad thickness of 10 normal untreated rats were measured during 10 days. The readings were within $1.8 \%$ of the mean baseline thickness.

Determination of yeast-cell numbers in the footpad. At post-mortem examination, animals were placed in a prone position with the hind legs extended toward the operator. Each foot was flooded with $95 \%$ alcohol and left to dry. This wash was repeated three times. The plantar tissue was then removed from the ventral surface of the foot with a sterile scalpel blade and forceps. The tissue was weighed, chopped coarsely with a scalpel blade and then homogenised in $9 \mathrm{ml}$ of sterile saline with a rotating teflon pestle in a heavy-walled glass tube (Tri- $R$ Instruments, Long Island, New York, USA). Serial tenfold dilutions were then made into pour plates of Sabouraud's dextrose agar containing chloramphenicol (Chloromycetin, Parke Davis and Co. Ltd) $0.1 \mathrm{mg} / \mathrm{ml}$. Numbers of yeast cells $/ \mathrm{g}$ of footpad were determined by colony counts.

Heat-killed organisms. To evaluate the effect of antigen alone on footpad swelling, doses of $10^{5}-10^{7}$ heat-killed $\left(100^{\circ} \mathrm{C}\right.$ for $\left.1 \mathrm{~h}\right)$ yeast cells in $20 \mu \mathrm{l}$ of saline were injected as above.

Cyclophosphamide treatment. Animals were made neutropenic by the implantation of three bone-cement disks containing cyclophosphamide. Disks $(1-\mathrm{cm})$ weighing $c .475 \mathrm{mg}$ were cast in a polyethylene mould. To make 20 disks, each containing $75 \mathrm{mg}$ of cyclophosphamide, $6 \mathrm{~g}$ of the polymer powder (Howmedica International Ltd, London) was mixed with $3 \mathrm{~g}$ of Endoxan (WB Pharmaceuticals), equivalent to $1.9 \mathrm{~g}$ of cyclophosphamide BP. The mixture was transferred to a well in the base of the mould and $3 \mathrm{ml}$ of liquid monomer was added and mixed carefully. The casting plate was then placed in position. Individual disks were implanted subcutaneously through an incision made along the dorsal midline, 4 days before footpad challenge. Plain disks were implanted in control animals and care was taken to ensure that infection did not occur at the implantation site. The procedure has been fully described by Ormrod et al. (1984).

Amphotericin treatment. Test animals were given amphotericin (Fungizone; E. R. Squibb and Sons Ltd, Hounslow, Middlesex) $5 \mathrm{mg} / \mathrm{kg}$ daily by intraperitoneal injection for 2 days before footpad infection. After the challenge, this dose of amphotericin was continued daily throughout the course of the study. Control animals were given $1 \mathrm{ml}$ saline instead of amphotericin. The anti-inflammatory effect of amphotericin was determined in a pilot experiment by observing the effect of the drug on carrageenan-induced footpad swelling. Details of the carrageenan model are given by Miller and Ormrod (1980).

\section{RESULTS}

\section{Inflammatory response to local infection}

When four groups of 10 rats were challenged in both hind feet with $10^{4}, 10^{5}, 10^{6}$ or $10^{7}$ viable yeast cells and the footpad thicknesses measured daily for 14 days, the peak inflammatory response for all inocula occurred in the first 2 days and then gradually subsided during the next 12 days. Host responses to inocula of $10^{4}$ and $10^{5}$ yeast cells were minimal, but $10^{6}$ and $10^{7}$ yeast cells induced maximum increases in footpad thicknesses of $27 \%$ and $55 \%$ respectively (fig. 1). Apart from the footpad swelling and 


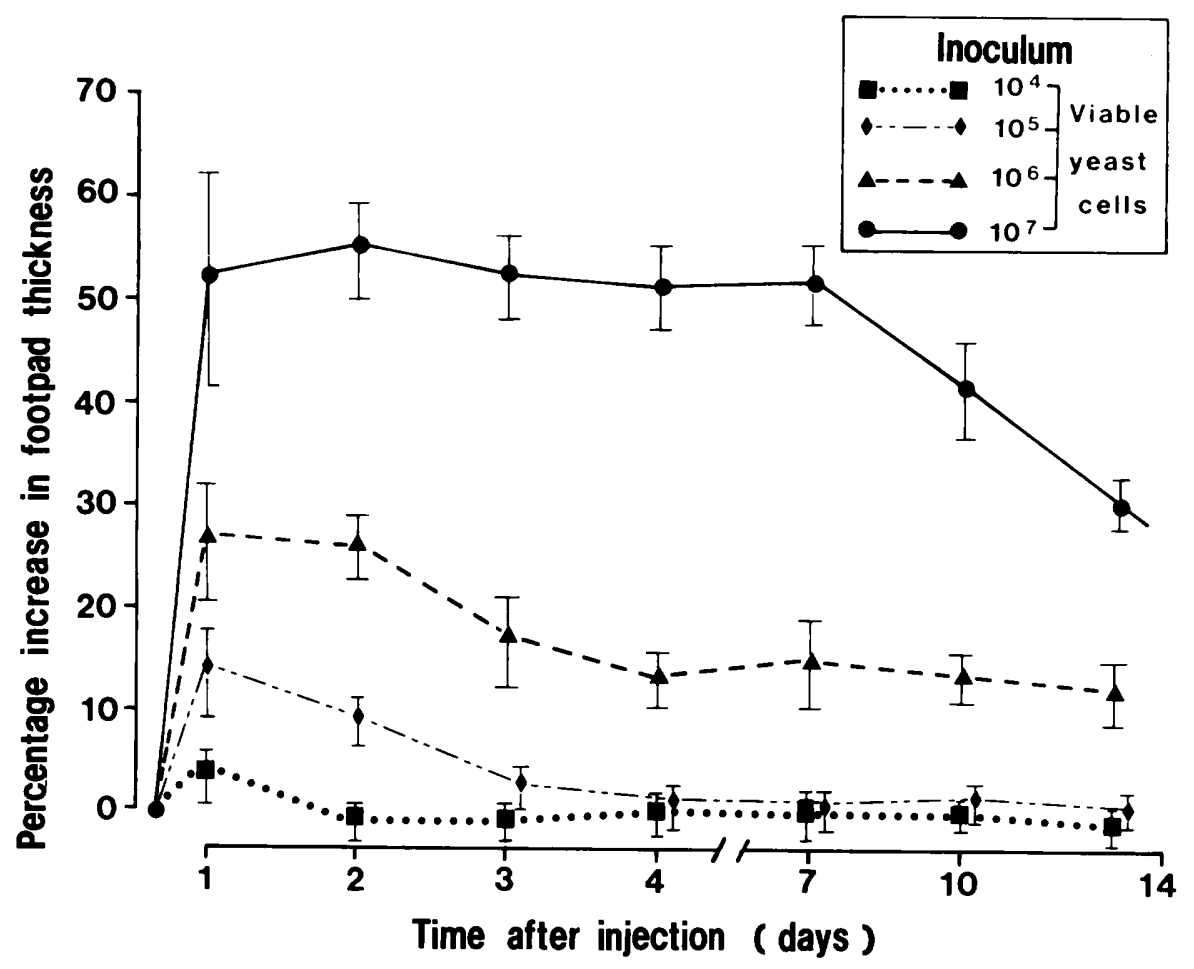

FIG. 1.-Footpad responses to a local infection induced by increasing doses of $C$. albicans injected directly into the plantar tissue. $(n=20 ; I=2 S D)$.

some redness, no other signs of infection were visible and no surface lesions developed. In the control groups challenged with heat-killed yeast cells $\left(10^{5}, 10^{6}\right.$ and $\left.10^{7}\right)$, the peak swelling was only one third of that observed with the equivalent inoculum of viable cells. Footpad thickness returned to normal within 4 days in the control groups, whereas footpads challenged with viable yeast cells remained swollen for more than 10 days.

\section{Correlation of footpad oedema with yeast cell numbers}

It was essential to demonstrate a close correlation between the inflammatory response and the course of infection before footpad swelling could be accepted as a substitute parameter for yeast cell numbers. This has been achieved through manipulation of the inflammatory response by treating animals with cyclophosphamide to depress immune capability, or amphotericin to limit cell replication. The effect of these manipulations on yeast-cell numbers in the footpads and on footpad oedema was then compared.

(a) Cyclophosphamide administration. Ten animals were treated with cyclophosphamide before footpad challenge. At the time of challenge the peripheral blood leukocyte count was $(1.7 \pm 0.6) \times 10^{9} / \mathrm{L}$ and remained at this level for at least 10 days. Both groups were challenged with $10^{6}$ viable yeast cells. Increases in the inflammatory response were observed in the immunocompromised group compared with the control group. The responses in the two groups were similar $24 \mathrm{~h}$ after challenge but thereafter 

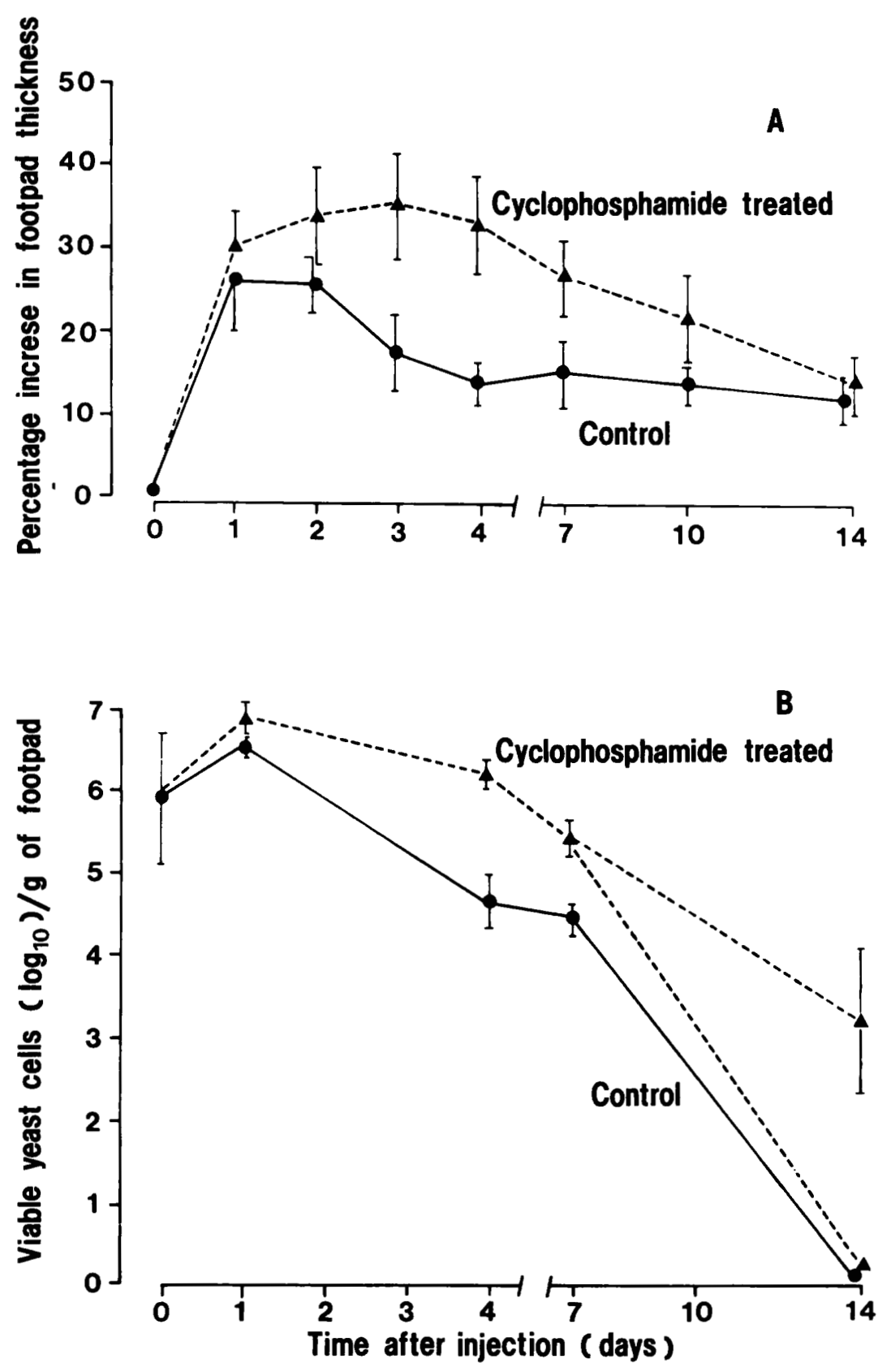

FIG. 2.-Effect on footpad swelling (A) and number of viable yeast cells (B) in untreated controls and in animals treated with cyclophosphamide $225 \mathrm{mg}$ after challenge with $C$. albicans $10^{6} \mathrm{cfu}(\mathrm{A}: \mathrm{n}=20$; B: $\mathrm{n}=12 ; \mathrm{I}=2 \mathrm{SD})$. 
inflammation subsided in the control group. In contrast, inflammation continued to increase in the cyclophosphamide-treated animals, and was maintained at a significantly higher level for at least 10 days (fig. 2A). In a further group of animals, numbers of viable yeast cells in the footpads of cyclophosphamide-treated and control animals (fig. 2B) closely followed the inflammatory-oedema profiles. Yeast-cell numbers up to
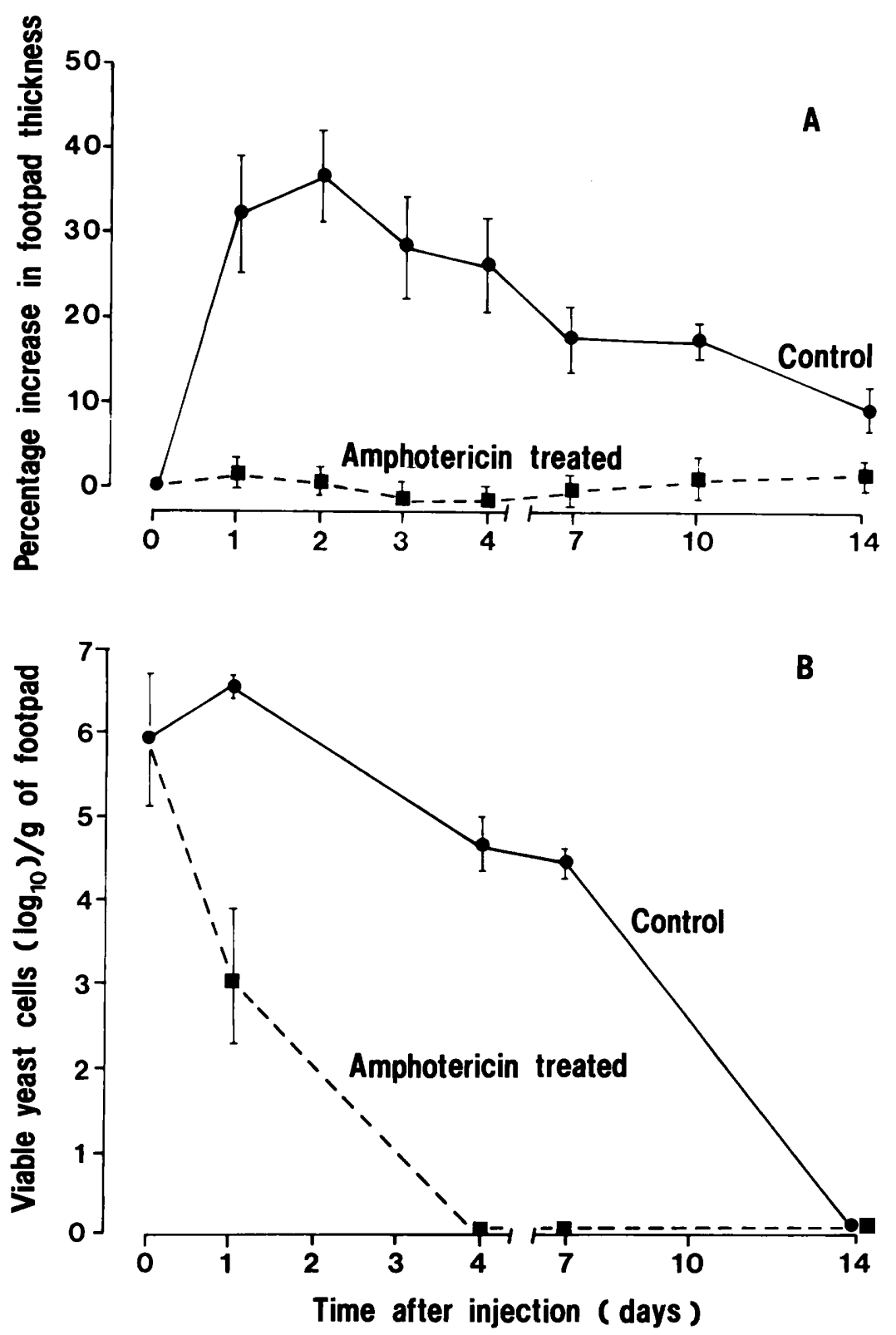

FIG. 3.-Effect on footpad swelling (A) and number of viable yeast cells (B) in untreated controls and in animals treated with amphotericin $5 \mathrm{mg} / \mathrm{kg}$ daily after challenge with $C$. albicans $10^{6} \mathrm{cfu}$. $(\mathrm{A}: \mathrm{n}=20 ; \mathrm{B}$ : $\mathrm{n}=12 ; \mathrm{I}=2 \mathrm{SD})$. 


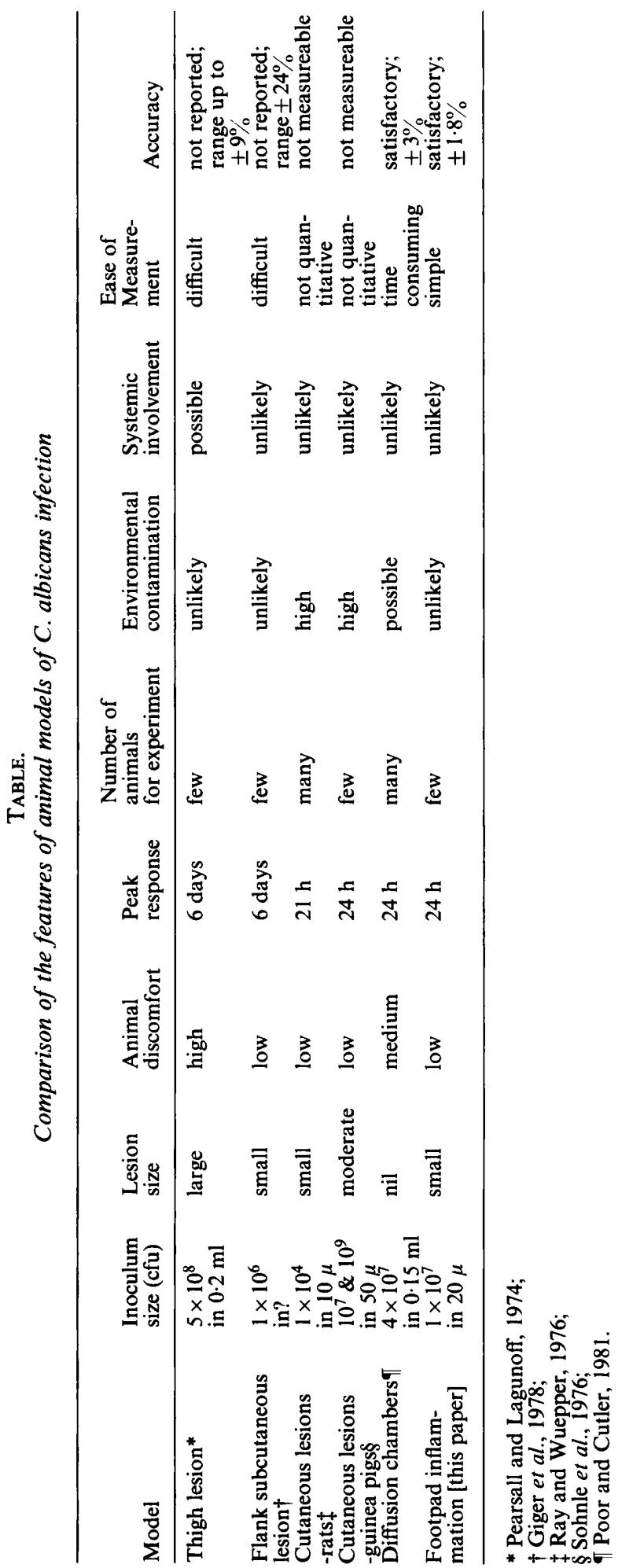


100 times that of the control group were found in the cyclophosphamide-treated animals. By the end of the study, infection had resolved in the control group and in $50 \%$ of the cyclophosphamide-treated animals.

(b) Amphotericin treatment. Ten animals were treated with amphotericin, daily, from 2 days before challenge to 14 days after challenge. A pilot experiment demonstrated that the drug had a marginal anti-inflammatory effect at the doses used. Saline was administered to a control group and all animals were challenged with $10^{6}$ viable yeast cells/footpad. Challenge of amphotericin-treated animals with yeast cells failed to induce footpad swelling (fig. 3A). The result corresponded with the quantitative mycological examination which showed that the infection had failed to become established and that yeast cells had been progressively eliminated during a 4-day period (fig. 3B).

\section{Discussion}

The footpad response to localised infection with $C$. albicans provides a procedure that allows continuous observations in individual animals. The numbers of yeast cells in the footpads correlated directly with the degree of swelling in normal, amphotericin treated and cyclophosphamide treated animals. Depression of immune competence with cyclophosphamide encouraged replication of yeast cells and increased the degree of footpad swelling. On the other hand, amphotericin caused a reduction in yeast-cell numbers and a reduction in footpad swelling.

Several models of $C$. albicans infection have been described and used to study the infectious process or the immune mechanisms involved in host protection. Their features, and the present model, are compared in the table. Several advantages of the model described are apparent: (1) the infection is localised and allows continuous assessment in individual animals; (2) because both hind feet are used, the number of observations for a given number of animals is doubled; (3) laboratory contamination is minimised by eliminating the need for tissue homogenisation and pour-plate counting; (4) environmental contamination from open lesions is also avoided; (5) the procedure is minimally invasive and causes the animals minimum discomfort.

Measurement of footpad swelling is a well established procedure that does not require special equipment or skills to achieve reproducible results. It should, therefore, be useful in the study of $C$. albicans and other fungal infections and in the assessment of new antifungal agents.

This study was supported by a grant from the Medical Research Council of New Zealand. We thank Rosalee Nash for editing and illustrating the manuscript.

\section{REFERENCES}

Giger D K, Domer J E, McQuitty J T 1978 Experimental murine candidiasis: Pathological and immune responses to cutaneous inoculation with Candida albicans. Infection and Immunity 19:499-509.

Gray D F, Jennings P A 1955 Allergy in experimental mouse tuberculosis. American Review Tuberculosis 72:171-195.

Miller T E, Ormrod D 1980 The anti-inflammatory activity of Perna canaliculus (N.Z. green lipped mussel). New Zealand Medical Journal 92:187-193.

Ormrod D J, Cawley S, Miller T E 1984 Extended immunosuppression with cyclophosphamide 
using controlled-release polymeric implants (bone cement). International Journal of Immunopharmacology (in press).

Pearsall N N, Lagunoff D 1974 Immunological responses to Candida albicans I. Mouse-thigh lesion as a model for experimental candidiasis. Infection and Immunity 9:999-1002.

Poor A H, Cutler J E 1981 Analysis of an in vivo model to study the interaction of host factors with Candida albicans. Infection and Immunity 31:1 104-1109.

Ray T L, Wuepper K D 1976 Experimental cutaneous candidiasis in rodents. The Journal of Investigative Dermatology 66:29-33.

Sohnle P G, Frank M M, Kirkpatrick C H 1976 Mechanisms involved in elimination of organisms from experimental cutaneous Candida albicans infections in guinea pigs. The Journal of Immunology 117:523-530.

Winter C A, Risley E A, Nuss G W 1962 Carrageenin-induced edema in hind paw of the rat as an assay for antiinflammatory drugs. Proceedings of the Society for Experimental Biology and Medicine 111:544-547. 